\title{
Espectrometria de Massa de Bombardeamento com Átomos Rápidos, FAB
}

\author{
M. HELENA FLORÊNCIO*
}

\begin{abstract}
A Espectrometria de Massa de Bombardeamento com Átomos Rápidos constitui um dos novos métodos de ionização que vieram permitir alargar o campo de aplicação da Espectrometria de Massa desde os domínios da

Química e da Física aos domínios da Geologia, Biologia, Medicina e Ciências do Ambiente. A sua popularidade ficou a dever-se à análise com sucesso de compostos polares e/ou termicamente instáveis, para além de se ter revelado extremamente útil para 0 estudo da química das soluções e superfícies líquidas.
\end{abstract}

\section{INTRODUÇÃO}

\subsection{Considerações genéricas}

Em muitas áreas da Ciência, e na Química em particular, é necessário possuir ou vir a adquirir um conhecimento exacto da identidade do objecto e das medições em curso ou a realizar. A resposta a questões como a estrutura e 0 teor de um dado composto pode ser considerada como uma necessidade básica, podendo dizer-se que as técnicas que fornecem informação sobre qualquer uma destas questões se tornam essenciais para 0 desenvolvimento científico. 0 grande sucesso da Espectrometria de Massa consiste precisamente no facto de, na grande maioria dos casos, poder dar resposta a estas duas questões, com versatilidade e sensibilidade $\left(\approx 10^{-13} \mathrm{~g}\right)$.

0 desenvolvimento, sem dúvida notável, que a Espectrometria de Massa sofreu nas últimas décadas, tem como base a sua grande versatilidade e sensibilidade a par da diversidade de informa-
Espectrometria de Massa Tandem, MS/MS, que possibilitou a identificação de compostos em quantidade vestigial (já atingindo os picogramas) em misturas complexas. Por outro lado, o aparecimento de novos métodos de ionização, de que o Bombardeamento com Átomos Rápidos, FAB, é um bom exemplo, veio tornar possivel 0 alargamento do campo de aplicação da Espectrometria de Massa desde os dominios da Quimica e da Física aos domínios da Geologia, Biologia, Medicina e Ciências do Ambiente.

A FAB só foi desenvolvida na década de 80 , mais concretamente em 1981 . por Barber e colaboradores [1]. A sua popularidade ficou a dever-se, em grande parte, à sua aplicação com sucesso à análise de compostos polares e/ou termicamente instáveis. Em paralelo e sobressaindo dos outros métodos de ionização, mesmo os mais modernos, tem-se revelado extremamente útil para 0 estudo da quimica das soluções e superficies líquidas, ao permitir o seguimento in situ, durante o bombardeamento, de muitas reacções químicas e bioquímicas.

\subsection{Técnicas de Feixes Energéticos}

As técnicas de desadsorção mais vulgamente usadas hoje em dia podem classificar-se como técnicas de Feixes Energéticos [2]. Consistem essencialmente na deposição da amostra numa superfície a qual é bombardeada com feixes de partículas energéticas, que podem ser iões $\left(\mathrm{Ar}^{+}, \mathrm{Xe}^{+}, \mathrm{Cs}^{+}\right.$, etc.), átomos neutros ( $\mathrm{Ar}, \mathrm{Xe}$, etc.) ou feixes de fotões com energias elevadas, da ordem dos 5 a $10 \mathrm{keV}$. A utilização de energias desta ordem de grandeza poderia parecer incompativel com a formação de espécies moleculares iónicas intactas. No entanto, nas técnicas de desadsorção, a energia do feixe primário não é transferida directamente para as moléculas da amostra uma vez que intervêm neste processo fenómenos de absorção, excitação e relaxação. As partículas primárias ou fotões penetram na superficie na qual a amostra se encontra adsorvida sendo a sua energia dissipada e conver-

tida em energia de excitação vibracional

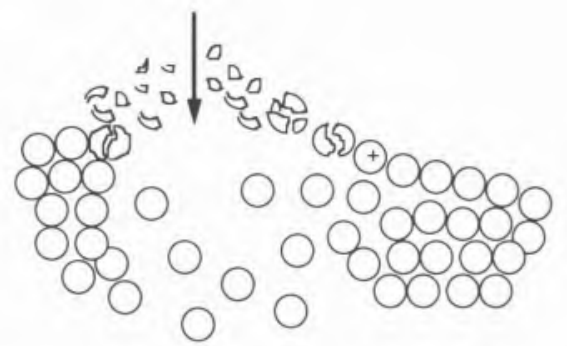

Figura 1. Representaçầo esquemática da

desadsorção de iôes

ou electrónica da rede sólida ou líquida que suporta a amostra. As moléculas próximas do ponto de impacto são pulverizadas (pulverização é um termo que se usa para designar a desadsorção induzida por partículas energéticas) para fora da superfície sob a forma de átomos ou iões com energia cinética elevada. À medida que a distância do ponto de impacto aumenta, vai-se dando a desadsorção de átomos, fragmentos iónicos e finalmente de iões moleculares intactos e moléculas neutras [3]. Na Figura 1 encontra-se representada esquematicamente a desadsorçāo de iões.

0 mecanismo geralmente aceite como responsável pela pulverização de pequenos iões a partir de uma matriz sólida é o modelo da cascata de colisões $[4,5]$, segundo o qual um feixe primário de partículas com energias da ordem dos keV ao penetrar na superfície vai sendo desacelerado, uma vez que vai perdendo energia cinética à medida que vai embatendo nas partículas das camadas e subcamadas superficiais. Numa descrição muito breve deste modelo, as particulas da superficie nas quais o feixe vai embater vão ser deslocadas indo colidir com outras num processo de colisões em cascata até que a energia do impacto seja dissipada num volume de superfície em torno do ponto de impacto. Ao mesmo tempo vai haver uma alteração da trajectória dos iões primários. No decurso da cascata muitas partículas podem adquirir momento na direcção da superfície e quando a sua energia for 
superior à energia de ligação superficial são projectadas para fora dessa superfície. Em FAB o mecanismo torna-se mais complexo em virtude da presença da matriz líquida, a irradiação da qual e sua consequente pulverização se considera como responsável pela emissão de iōes moleculares estáveis e de energia interna relativamente baixa.

De entre as técnicas de desadsorção mais vulgarizadas comercialmente e mais correntemente utilizadas merecem especial menção, pela vasta gama de compostos polares e não voláteis a que são aplicadas com sucesso, a Espectrometria de Massa de lões Secundários, SIMS [6] e o Bombardeamento com Átomos Rápidos, FAB [1].

A Espectrometria de Massa de lões Secundários, SIMS, é, pelas suas características, uma técnica destrutiva da superficie a ser bombardeada. Este facto, em particular no caso de moléculas orgânicas adsorvidas no suporte sólido, conduz à obtenção de um feixe de iões resultantes da ionização da amostra, iões secundários, feixe este intenso, mas de curta duração. Como a destruição da superficie da amostra pode ser muito rápida, da ordem de poucos segundos, ela vai conduzir ao rápido desaparecimento do sinal, o que pode tornar difícil não só realizar um varrimento das massas de modo a obter um espectro completo, como obter um feixe suficientemente estável no período de tempo

Figura 2. Representaçăo esquemática da ionização em $F A B$ necessário para medição de massas exactas. A técnica de SIMS continua no entanto a ser correntemente utilizada para compostos de difícil solubilização numa matriz liquida.

A Espectrometria de Massa de Bombardeamento com Átomos Rápidos, $F A B$, foi desenvolvida com o objectivo de solucionar o problema da brevidade do sinal que ocorria frequentemente em SIMS. Com esta finalidade a amostra era dissolvida ou suspensa numa matriz líquida [1], conjunto que seria em seguida bombardeado (Figura 2).

Este sistema, ao permitir que o soluto circulasse livremente na solução, assegurava 0 fornecimento de novas moléculas deste para a superfície, promovendo assim a renovação contínua da superficie exposta ao bombardeamento, 0 que tem como resultado a obtenção de um sinal estável e de longa duração (em geral alguns minutos). 0 glicerol, devido à sua baixa tensão de vapor que fazia com que não fosse rapidamente evaporado pelo sistema de vácuo, foi das primeiras matrizes utilizadas.

Para além da inovação da matriz líquida relativamente à técnica de SIMS, Barber [1] também substituiu o feixe de iões por um feixe de átomos o que parecia trazer vantagens consideráveis. Por um lado 0 feixe neutro não era afectado pelos campos magnético e eléctrico do sistema e o espectrómetro podia ser rapidamente utilizado quer para iões positivos quer para iões negativos e por outro, evitava-se a acumulação de carga em muitas substâncias orgânicas que são isoladoras, o que poderia conduzir

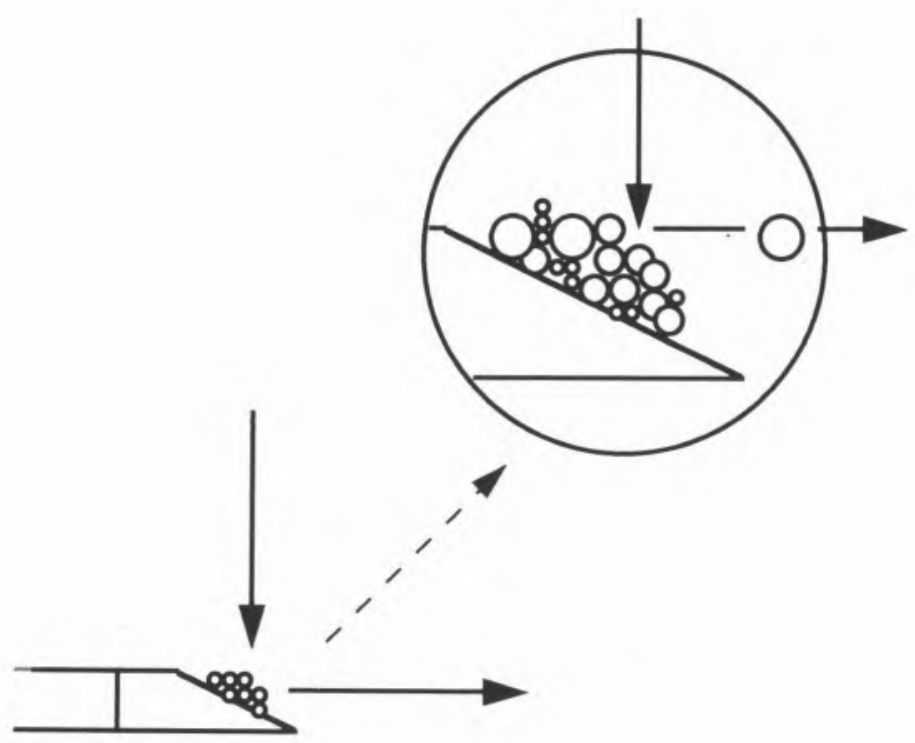

ao deslocamento ou mesmo até à supressão de picos. Já se verificou, no entanto, que a carga nas partículas primárias constitui um parâmetro muito menos importante do que a utilização de uma matriz líquida, este sim um parâmetro crítico, razão fundamental da importância da FAB. Têm aliás sido usados com bons resultados feixes primários de iões de césio [7], os quais podem ser mais facilmente focados, conduzindo a uma maior eficiência de ionização e permitindo assim atingir limites de detecção mais baixos. Na literatura encontra-se muitas vezes o termo SIMS líquido, LSIMS, para designar a utilização de feixes primários de iões, em FAB.

$\left(\mathrm{CH}_{3}\right)_{3} \mathrm{As}^{+} \mathrm{CH}_{2} \mathrm{COO}$

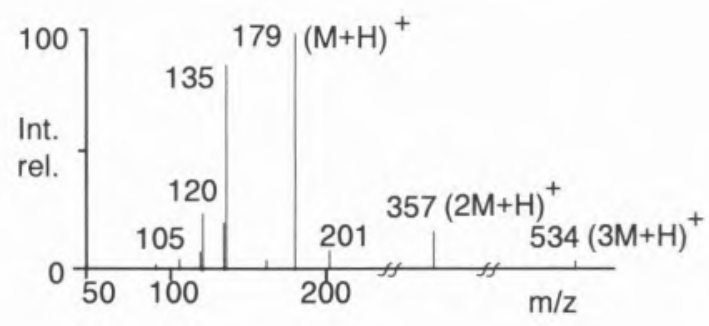

Figura 3. Espectro de massa FAB da arsenobetaína

\subsection{Domínios de Aplicação}

As principais aplicações foram de início no domínio das biomoléculas por se tratar em geral de compostos muito polares e termicamente instáveis, difíceis de ionizar por outros métodos, mas rapidamente se estenderam ao domínio dos compostos organometálicos e compostos de coordenação. Na Figura 3 encontra-se representado o espectro de massa FAB de um composto organometálico, neste caso particular a arsenobetaína. Convém, no entanto, mencionar que a existência de uma matriz líquida, que tem provado ser um sucesso para a análise de compostos orgânicos e bio-orgânicos, tem sido por vezes um problema para compostos inorgânicos, dada a dificuldade de solubilização de muitos destes compostos nessa matriz. Por esta razão, o crescimento das aplicações em química inorgânica tem sido mais lento.

É, no entanto, possivel afirmar hoje em dia que se trata de uma técnica com aplicação em quase todos os campos em que a análise molecular é útil. 


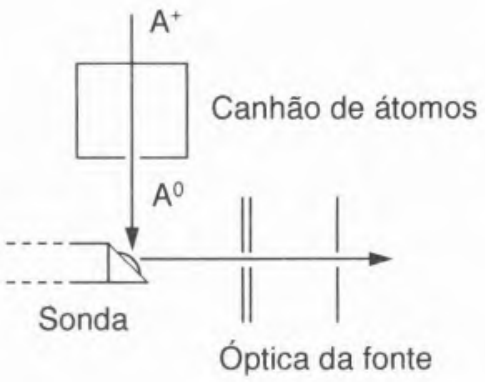

Figura 4. Representação esquemática de uma fonte $F A B$

\section{INSTRUMENTAÇ̃̃O}

\subsection{A Fonte FAB}

A fonte $F A B$ é constituida essencialmente por um canhão de átomos, em que os gases mais usados são xénon $\mathrm{e}$ árgon e uma sonda com uma ponta metálica, que funciona como alvo (Figura 4). Os iões secundários produzidos pelo embate do feixe de átomos são extraídos por um eléctrodo extractor e focados por um sistema de lentes electromagnéticas que os dirige para 0 analisador

\subsection{Canhão de Átomos}

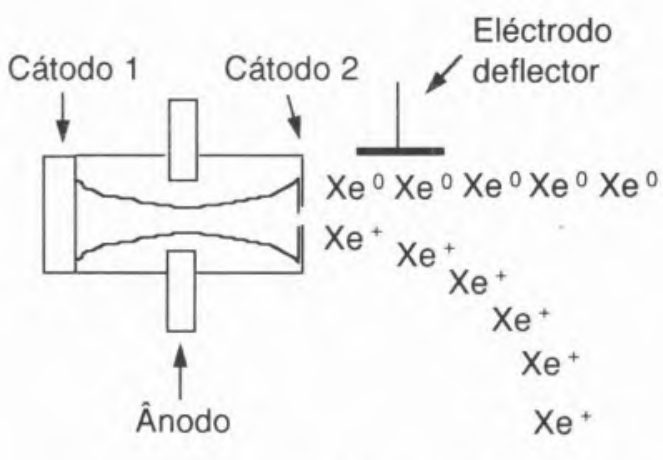

Figura 5. Esquema de um canhão de campo de sela

Inicialmente o feixe de átomos energéticos era obtido através da produção de um feixe de iões de um gás inerte, numa fonte de iões do tipo Impacto
Hoje em dia usam-se fontes mais compactas, de fácil montagem, em que não é necessário existir uma câmara exterior para transferência de carga. Os iões remanescentes são deflectidos por meio de um método simples de deflecção electrostática. Existem vários modelos, sendo o de campo de sela, com cátodo frio, $[8,9]$ um dos mais vulgarizados. Neste modelo (Figura 5) os electrōes vão descrever trajectórias oscilantes entre dois cátodos, sob a acção de um campo electrostático. 0 feixe de iões é convertido num feixe de átomos com sensivelmente a mesma energia, por meio de mecanismos de transferência de carga com moléculas de gás não ionizado e de captura electrónica de electrões lentos ou de electrões secundários produzidos por bombardeamento do cátodo com iões. [10]:

De um modo geral tem-se que

$$
\begin{gathered}
\Delta E=0 \\
A_{\alpha}{ }^{+}+A_{B} \rightarrow A_{\alpha}+A_{B}{ }^{+}
\end{gathered}
$$

Iões rápidos Átomos rápidos Energ. Cinética $=V \quad$ Energ. Cinética $\approx V$

A corrente é controlada fazendo variar 0 fluxo de gás e a voltagem entre 0 ânodo $\mathrm{e} 0$ cátodo.

\subsection{Alvo}

É constituido por uma pequena tira metálica, que pode ser aquecida e é colocada na extremidade da sonda. Quando introduzida na fonte vai interceptar 0 feixe de átomos a um ângulo fixo relativamente ao feixe de átomos e que irá depender do formato do alvo [11] e do tipo de instrumento. É em geral de aço inoxidável, mas também tem sido utilizado cobre, molibdénio e prata entre outras substâncias.

\section{MECANISMOS DE FORMAÇ̃̃O DE IÕES}

$A$ formação de iões em $F A B$ resulta de mecanismos complexos que ainda não se encontram bem esclarecidos. Têm sido várias as teorias propostas para explicar esses mecanismos e sua ocorrência temporal (antes, durante ou pós bombardeamento), sendo múltiplos os exemplos na literatura apresentados como evidência para um ou outro caso. No actual estado de conhecimentos e sem prejuízo da ocorrência de outros mecanismos, admite-se que os iões formados em FAB têm essencialmente duas origens: (i) Formados em solução antes do bombardeamento a partir de espécies pré-ionizadas (teoria dos iões pré-formados); (ii) Formados na fase gasosa durante a dissipação de energia do feixe primário, em que se dá a ionização de espécies neutras desadsorvidas. Ambos os fenómenos parecem participar no processo de emissão de iões, sendo a contribuição de cada um desses processos função das condições experimentais e da natureza da amostra.

Um amplo esclarecimento, no entanto, é extremamente dificultado por factores de vária ordem, tais como 0 desconhecimento da composição da fase gasosa acima do alvo e em especial da região de pressão elevada situada imediatamente acima, vulgarmente designada por "orla" (selvedge), ou da energia dos seus componentes. Para além destes factores, os iões que se observam no espectro não resultam exclusivamente de um processo de desadsorção puro e sim de uma sucessão de fenómenos em que não só a energia dos iões mas também a sua natureza química pode ser fortemente modificada.

\subsection{Iões Pré-formados}

0 Modelo do Precursor [12], inicialmente desenvolvido para SIMS, pressupõe a existência na superfície, anteriormente a qualquer bombardeamento, de um precursor do ião secundário que vai ser ejectado. Como resultado da energia gerada na superfície na região próxima do impacto, irá dar-se a evaporação rápida $\left(\approx<10^{-12} \mathrm{~s}\right)$ dos precursores não fragmentados. Em FAB, a existência de espécies pré-ionizadas em solventes e/ou numa matriz líquida, os iões pré-formados, que corresponde à ideia de precursor, leva a que sejam directamente pulverizados diversos iões solvatados e iões da matriz. Vários têm sido os argumentos em favor deste mecanismo [13-16]. Muitos destes argumentos baseiam-se no aumento de intensidade da corrente iónica quer de moléculas protonadas quando aumenta a acidez da matriz, quer de aniões formados pela perda de um protão em soluções básicas. De facto tem-se verificado experimentalmente que 0 rendimento em iões secundários é mais elevado para sais orgânicos pré-formados e espécies protonadas e cationizadas. No entanto. recentemente surgiram outras explicações para esses efeitos [17], explicações 
que envolvem variações de solubilidade, actividade superficial, volatilidade e quimica induzida pela radiação. Outros argumentos em favor de um mecanismo em solução são aqueles que envolvem a medição de propriedades da solução e as relacionam com a abundância relativa dos iões secundários. Um exemplo são as medições de condutividade realizadas por Huang e Wu [13]. Para estes autores, os iões secundários formados em FAB a partir de compostos iónicos e compostos polares resultam essencialmente de iões pré-formados em solução. Ainda em suporte da teoria dos iões préformados, é de mencionar o aparecimento de moléculas protonadas multiplamente carregadas, $\mathrm{MH}^{2+}$ e $\mathrm{MH}^{3+}$, tal como apareceram em soluções de insulina bovina em glicerol quando acidificadas por meio de ácidos fortes, reflectindo $0 \mathrm{pH}$ da solução [14]. Tais processos de protonação múltipla raramente são observados em ionização química.

Em resumo, é hoje aceite que há iōes formados em FAB que resultam da existência de iões pré-formados, como é o caso de compostos iónicos que existem como iões na solução e são detectados como iões. 0 problema consiste em saber em que medida e em que casos este processo é mais ou menos eficiente que os processos em fase gasosa, processos que também não podem ser excluídos.

\subsection{Ionização em Fase Gasosa}

Vários autores têm sugerido que a formação de iões em FAB ocorre em fase gasosa por meio de um processo de Ionização Química em que os iões da matriz actuam de um modo análogo aos iões do gás reagente $[18,19]$. Para além das mais variadas experiências para sustentar esta teoria, Budzikiewicz e colaboradores [19] procuraram demonstrar por meio de cálculos, uma vez que não é possivel realizar medições directamente, que nas fontes $F A B$ prevaleciam condições comparáveis às condiçōes típicas de Ionização Química, $\mathrm{Cl}$.

Pode dizer-se que existe já um certo consenso de que, para espécies não iónicas, o principal mecanismo de formação de iões é o mecanismo em fase gasosa. Não se encontra no entanto ainda convenientemente esclarecido o local onde estas reacções ião-molécula se dão, se numa cavidade de gás energético ou na "orla" (selvedge), região de plasma entre a fase condensada e a fase gasosa, muito

\section{lões pré-formados}

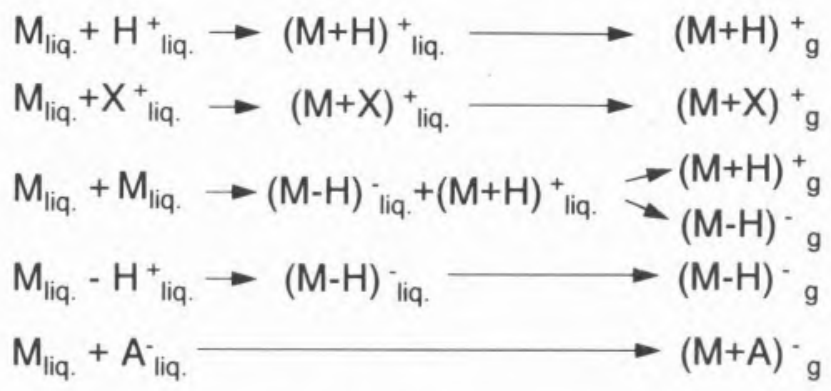

Fase gasosa

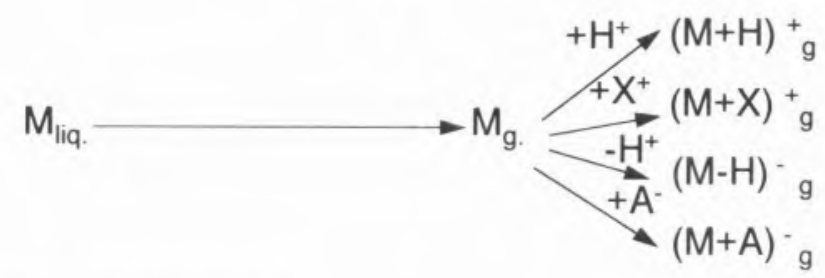

Figura 6. Mecanismos de formação de iōes

quente e de pressão elevada, que se forma imediatamente acima da superficie liquida durante 0 bombardeamento. 0 modo como a emissão a partir do líquido se dá e se ela pode ser vista em termos de uma transição brusca de fase de um líquido com uma grande densidade energética, como por exemplo a sugerida no modelo de "explosão de fase" [20], permanece uma questão em aberto.

Na Figura 6 estão resumidamente indicados os principais mecanismos de formação de iões que ocorrem quer na fase condensada quer na fase gasosa.

\section{PARÂMETROS RELEVANTES}

\subsection{0 feixe primário}

Apesar da importância do feixe primário na obtenção de espectros $F A B$, são raros os estudos em que é investigada a influência no espectro de parâmetros como a massa das partículas do feixe ou a sua energia. Uma vez que é essencial que a comparação seja feita sob condições controladas, a dificuldade na obtenção de resultados reprodutiveis, que resulta não só da natureza do próprio processo de pulverização como de variações que ocorrem no canhão de átomos, pode estar na origem do reduzido número de estudos realizados.

\subsubsection{Massa das partículas}

Tem-se aceitado, embora de um ponto de vista muito genérico, que quanto maior a massa das partículas, mais eficiente é a produção de iões secundários. Esta afirmação deve ser usada com uma certa cautela, pois nem sempre é verdadeira. Num estudo usando xénon, árgon e néon [21], verificou-se que o xénon era mais eficiente que 0 árgon e 0 néon, para ionização de espécies polares, tendo-se concluido que 0 rendimento em iões pseudo-moleculares, $[\mathrm{M}+\mathrm{H}]^{+}$, era aproximadamente proporcional à massa das partículas, para essas espécies. Para espécies não polares a influência da massa das partículas já não parecia significativa, 0 que foi atribuido ao facto destas espécies não serem tão facilmente protonadas. Também se verificou que partículas de peso atómico elevado relativamente ao xénon não alteram significativamente a proporção de iões pseudomoleculares no espectro, nem sequer são necessariamente mais eficientes para ionização de espécies de massa molecular elevada. Com o mercúrio (PA-200), por exemplo, os resultados que se obtiveram, em condições tanto quanto possivel idênticas dadas as limitações inerentes, são sensivelmente semelhantes aos obtidos com xénon. Quanto a partículas poliatómicas de massa molecular $>200$, com 0 canhão de campo de sela não se tem conseguido obter um feixe de partículas eficiente [22]. 


\subsubsection{Energia do Feixe}

A energia do feixe primário deve ser um factor a ter em conta na formação de iões secundários [23]. Com o aumento da energia do feixe tem-se observado, tanto no modo positivo como no modo negativo, 0 aumento do sinal em termos absolutos, até um dado valor de energia. 0 decréscimo observado para valores de energia elevados tem sido entendido como resultante da penetração profunda do feixe na superfície, fazendo com que a deposição de energia se dê numa região demasiado profunda para uma ionização eficiente das moléculas à superfície.

No entanto, também se verificou que apesar de haver um aumento da intensidade do sinal relativo aos iões secundários com 0 aumento da energia do feixe primário, ocorre um decréscimo da fragmentação. Para energias do feixe primário mais elevadas observa-se menos fragmentação devido à desadsorção de um maior número de iões moleculares de baixa energia, uma vez que, para energias mais elevadas do feixe primário, a transferência de energia se irá dar para um maior volume de amostra.

\subsubsection{Fluxo primário}

Seria de esperar que o sinal da amostra aumentasse linearmente com 0 aumento de fluxo do feixe e a maior parte das experiências com FAB são realizadas para fluxos primários relativamente elevados. No entanto, a relação sinal/fluxo não é linear [23]. Para valores elevados de fluxo vai haver não só um aumento substancial da abundância dos iões da matriz como um aumento significativo do fundo ou ruído químico. Como resultado o limite de detecção irá subir.

Por outro lado, as reacções de redução induzidas pelo impacto do feixe, que ocorrem em maior ou menor grau, dependendo das características da amostra e da matriz, também vão aumentar com 0 aumento do fluxo.

\subsection{A Matriz}

É com razão que a matriz tem sido considerada como 0 parâmetro mais importante em FAB $[24,25]$. A sua importância é reconhecida não só pelo facto de permitir a renovação contínua de moléculas intactas da amostra à superfície (i.e. de moléculas que ainda não sofreram alterações devido ao impacto), como também pelo papel fundamental que desempenha na formação dos iões. A matriz tem ainda como função promover a dissipação da energia resultante do impacto, de modo a permitir que as moléculas da amostra recebam uma quantidade de energia interna moderada.

\subsubsection{Propriedades}

Resumidamente pode dizer-se que uma combinação dos fenómenos de evaporação da matriz, difusão das moléculas da amostra e sua solubilização, asseguram a renovação da superficie que vai ser bombardeada, devendo ao mesmo tempo dar-se a remoção dos produtos resultantes de reacções químicas induzidas pelo impacto das partículas primárias altamente energéticas, antes do impacto seguinte (auto-purificação). As propridades físicas e quimicas da matriz estão pois envolvidas em todas as facetas do processo de emissão de iões .

De entre os vários requisitos a que a matriz deve obedecer devem especialmente ter-se em conta os seguintes que são fundamentais [26]: (i) Deve dissolver o composto a ser analisado, com ou sem a ajuda de um co-solente ou aditivo. Irá assim fomentar a difusão das moléculas do composto para a superfície. Em muitos casos em que a FAB parece falhar esse facto pode ficar a dever-se a uma reduzida solubilização da amostra. (ii) Deve ter volatilidade relativamente baixa, nas condições de vácuo do espectrómetro. Uma matriz muito volátil pode dar origem a espectros de curta duração. (iii) Idealmente não deve reagir quimicamente com a amostra ou deverá fazê-lo de um modo reprodutivel e previsivel. A matriz deve também ser um composto aprovado pelas normas de segurança, não deve causar a contaminação do espectrómetro de massa ou essa contaminação deve ser reduzida. Deve ainda ser um composto estável e de composição constante.

0 glicerol tem sido a matriz mais exaustivamente usada, dadas as suas características (viscosidade, relativa volatilidade), mas também têm sido usadas muitas outras substâncias e a lista de possiveis matrizes já é vasta.
Para conseguir uma ionização eficiente da amostra seria, de facto, necessário conhecer as propriedades físicas e quimicas tanto da amostra como da matriz, razão pela qual têm sido publicadas tabelas com valores de propriedades físicas para as matrizes mais usadas [27].

Pode, portanto, dizer-se que a selecção adequada da matriz para cada caso é condição essencial para obtenção de espectros $F A B$ de boa qualidade.

\subsubsection{Acidez e basicidade}

A acidez ou basicidade do solvente relativamente à amostra pode ser crítica para a produção de iões com intensidade significativa. É sabido que a adição de ácidos no modo positivo e a adição de bases no modo negativo aumenta frequentemente a intensidade dos iões $[\mathrm{M}+\mathrm{H}]^{+}$e $[\mathrm{M}-\mathrm{H}]^{-}$respectivamente. A explicação mais usual é a de que 0 aumento da intensidade do sinal resulta do aparecimento de iões pré-formados como resultado da adição de ácidos ou bases. É o que se observa no caso do vermelho de metilo quando ácido clorídrico ou hidróxido de sódio é adicionado à matriz glicerol [28]. No modo positivo por exemplo, a razão $[\mathrm{M}+\mathrm{H}]^{+} /$ $\mathrm{M}^{+}$. passa de $15,1 \mathrm{em}$ meio ácido, para 7,6 e 6,7 respectivamente em meio neutro e meio básico. 0 efeito de $\mathrm{pH}$ observado, apesar de significativo é relativamente pequeno, 0 que se fica a dever ao facto do vermelho de metilo não ser um composto superficialmente activo. Também se observou, à semeIhança de outros casos verificados na literatura, entre os quais se poderia citar como exemplo o efeito observado por Malorni e colaboradores [29] em soluções de péptidos após a adição de ácidos, que ao contrário das soluções neutras, as soluções ácidas e básicas permitiam a obtenção de um sinal mais duradouro. Neste caso particular atribuiu-se este fenómeno ao facto do vermelho de metilo possuir na sua estrutura tanto uma função ácida como uma função básica, pelo que a adição de uma base ou de um ácido poderia promover uma maior concentracão à superfície de moléculas do composto. Por outro lado o possivel ganho em sinal resultante das variações de $\mathrm{pH}$ poderia ser compensado pela baixa actividade superficial do composto. 


\section{EFEITOS DE SUPERFICIE}

\subsection{Actividade superficial e qualidade dos espectros de massa FAB}

A existência de carga em solução constitui um importante factor para obtenção de espectros FAB. No entanto, uma substância pode possuir carga em solução e mesmo assim ser dificil obter um espectro de boa qualidade pelo facto de não ser superficialmente activa, isto é, de não fazer baixar acentuadamente a tensão superficial. É o caso por exemplo do vermelho de metilo, cujo sinal se apresenta extremamente instável em solução neutra [28]. Por outro lado, substâncias superficialmente activas podem ser rapidamente detectadas em quantidades da ordem dos ppm enquanto que outras que não possuem actividade superficial ou que têm uma actividade superficial negativa relativamente ao solvente permanecem sem serem detectadas, mesmo aumentando a sua concentração [30]. Além disso, substâncias que, quando puras, dão origem a espectros de massa, poderão não aparecer no espectro quando presentes em misturas de compostos superficialmente mais activos [31].

A actividade superficial é pois um factor que tem uma enorme influência no aparecimento de espectros de massa FAB.

É interessante verificar que a concentração micelar crítica, C.M.C., constitui um parâmetro importante no contexto da FAB. Assim, foi possivel observar para um conjunto de surfactantes para os quais os valores da C.M.C. em glicerol são conhecidos que, com 0 aumento da cadeia, o valor da C.M.C. diminui enquanto que o sinal no espectro aumenta, indicativo de que estas substâncias tendem a povoar a superfície por ordem crescente do comprimento da mesma [32]. Por outro lado a C.M.C. corresponde também aproximadamente ao ponto em que 0 sinal do solvente desaparece do espectro de massa [33].

Os fenómenos de superficie têm pois extrema importância no aparecimento de espectros de massa FAB. Na ausência de outros efeitos, os espectros deveriam reflectir a composição da solução. No entanto é necessário ter em conta que um espectro pode ser representativo da superfície de uma solução e de que essa superfície pode ter uma composição muito diferente da solução.

\subsection{Importância da utilização de surfactantes}

Os surfactantes podem ser usados para maximizar a corrente iónica para uma dada substância, mas é essencial que não contribuam com um espectro interferente próprio. Consegue-se uma interferência mínima quando se adicionam surfactantes negativamente carregados em experiências no modo positivo ou surfactantes positivamente carregados em experiências no modo negativo.

Por um lado a adição de surfactante pode originar, tanto no modo positivo como no modo negativo, a obtenção de espectros mais "limpos" uma vez que há uma redução nítida dos iões característi$\cos$ da matriz $[28,32]$. Por outro lado a adição de surfactante, ao promover um transporte regular de iões e moléculas para a superficie, pode conduzir à estabilização da corrente iónica como se pode ver na Figura 7 para o vermelho de metilo em meio neutro [28].

Deve no entanto ter-se em conta que após adição do surfactante 0 ambiente químico em volta da amostra muda, 0 que pode ter consequências para 0 processo de ionização.

Entre outros efeitos que se podem observar, é ainda de mencionar 0 aumento da abundância de iões [M+nH]+ $(n>1)$ na presença de surfactante, para 0 qual irá contribuir 0 transporte regular para a superfície de moléculas e iões pré-formados pelas micelas, tendo sido propostos os seguintes mecanismos [28] :

$$
\begin{aligned}
& M+M+\cdot \rightarrow[M-n H]+[M+n H]^{*} \quad n>1(1) \\
& M+[M+H]^{*} \rightarrow[M-n H]+[M+(n+1) H]^{+} n \geq 1(2) \\
& M+[M-H]^{*} \rightarrow[M-(n+1) H]+[M+n H]^{+} \quad n>1 \quad(3)
\end{aligned}
$$

Os surfactantes podem ainda ser usados para dominar a superficie de tal modo que a actividade superficial relativa dos componentes de misturas se torne irrelevante 0 que poderá ter como consequência uma nivelação do sinal [34].

Os surfactantes desempenham pois um importante papel na optimização de espectros de massa quando a técnica utilizada é uma técnica sensivel à composição da superficie como é 0 caso da FAB.

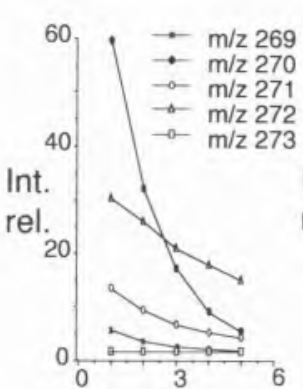

(a) no varrimento

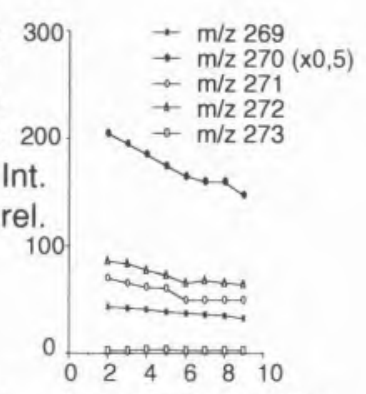

(b) $\mathrm{n} \div$ varrimento
Figura 7. Evoluçăo da intensidade de picos do vermelho de metilo, no modo positivo. (a) solução neutra e (b) solução neutra contendo sulitato de dodecilo e litio, SDL.

\section{FENÓMENOS DE OXIDAÇÃO-REDUÇÃO}

\subsection{Mecanismos e correlações}

Em Espectrometria de Massa FAB ocorrem com frequência, durante 0 bombardeamento, reacções químicas induzidas pelo impacto do feixe energético, as quais podem conduzir à alteração da estrutura das moléculas da amostra. De entre estas reacções merecem especial menção, pela importância de que se revestem, as reacções de redução da amostra. Ainda não foram bem estabelecidos os mecanismos através dos quais a redução ocorre, nem se sabe qual a contribuição exacta da matriz neste contexto, mas o fenómeno de redução é certamente facilitado pelo facto de, durante o bombardeamento, ocorrerem numerosas colisões na matriz. Estas colisões, que têm lugar durante o bombardeamento, conduzem à formação de espécies atómicas e radicais livres, libertação de electrões e abstracção de átomos de hidrogénio, o que vai obviamente facilitar os fenómenos de redução.

Para explicar os fenómenos de reduçāo observados para várias classes de compostos, podem ainda citar-se genericamente sucessivas protonações e reduções por meio de um electrão e protonação múltipla seguida de redução por um ou dois electrões [35-37].

Foi igualmente sugerida uma correlação da intensidade do sinal com os potenciais de redução, como se pode ver na Tabela 1 para os corantes azul de metileno e rodamina [38]. 0 azul de metileno é 0 corante que sofre maior redução, tal como seria de esperar face aos valores de potencial de meia onda daqueles compostos. 
Tabela 1 - Correlação entre os potenciais de meia onda do azul de metileno e rodamina e a intensidade relativa de picos nos espectros de massa $\mathrm{FAB}$ destes corantes, usando várias matrizes

\begin{tabular}{|c|c|c|c|c|c|c|}
\hline & \multicolumn{6}{|c|}{ Matriz } \\
\hline & Teórico & Glicerol & Tioglicerol & Sulfolano & HEDS & NBA \\
\hline M & 100 & 35 & 100 & 100 & 97 & 100 \\
\hline$M+1$ & 20 & 80 & 87 & 97 & 100 & 52 \\
\hline$M+2$ & 6 & 100 & 71 & 73 & 38 & 28 \\
\hline \multicolumn{7}{|c|}{$\begin{array}{l}\text { R o d a m i n a }\left(E_{1 / 2}=-0,825\right) \\
443\left(M^{*}\right)\end{array}$} \\
\hline & \multicolumn{6}{|c|}{ Matriz } \\
\hline & Teórico & Glicerol & Tioglicerol & Sulfolano & HEDS & NBA \\
\hline M & 100 & 100 & 100 & 100 & 100 & 100 \\
\hline$M+1$ & 32 & 33 & 34 & 42 & 33 & 36 \\
\hline$M+2$ & 5 & 9 & 8 & 6 & 9 & 7 \\
\hline
\end{tabular}

Teórico, contribuição isotópica teoricamente calculada; HEDS, Dissulfureto de hidroxietilo; NBA, Álcool Nitrobenzilico

A selecção da matriz também tem influência no mecanismo de redução, tal como se pode ver na tabela anterior. Assim a redução é máxima quando a matriz é glicerol, cujo potencial de redução é de $\approx 0,1 \mathrm{~V}[25]$ e minima quando a matriz é o álcool nitrobenzílico, composto reconhecido pelas suas propriedades de captura de electrões.

Face aos resultados experimentais obtidos com várias matrizes, em especial para corantes com tendência a reduzirem-se, foi sugerido [38] que o poder redutor da matriz decrescia pela ordem: Glicerol > Sulfolano > Tioglicerol > Dissulfureto de Hidroxietilo (HEDS) > Álcool Nitrobenzílico (NBA).

Este tipo de correlação não pode, no entanto, ser generalizada pois a redução que ocorre em FAB é um fenómeno complexo que pode ser influenciado por outros factores como parâmetros instrumentais e concentração da amostra. Contudo, o poder de uma dada matriz para reduzir drasticamente ou mesmo suprimir os fenómenos de redução da amostra, é amplamente reconhecido.

A selecção da matriz permite também optimizar a intensidade dos picos resultantes de processos especificos como é o caso dos picos devidos a fenómenos de redução da amostra.

Em resumo, a selecção cuidadosa da matriz pode conduzir à supressão de processos que ocorrem na fonte $F A B$ e tornar-se extremamente útil não só para optimizar a informação que a espectrometria de massa $F A B$ pode fornecer. como para permitir 0 estudo de processos químicos específicos.

\section{DESENVOLVIMENTO E PERSPECTIVAS FUTURAS}

\subsection{Introdução de novas matrizes e aditivos}

As propriedades físicas e quimicas das matrizes clássicas têm sido publicadas em vários artigos de revisão, em geral com a indicação do tipo de compostos para que são mais adequadas. Tem igualmente vindo a ser estudada a utilização de compostos mais especifi$\cos$, sendo regularmente apresentados novos candidatos a matrizes tais como álcoois de cadeia longa, ácido sulfúrico, éteres, etc.. No que respeita aos aditivos a lista também vai aumentando rapidamente, incluindo ácidos com actividade superficial e reagentes de oxi-redução.

\subsection{FAB de fluxo contínuo}

0 acoplamento das técnicas de cromatografia líquida à Espectrometria de Massa foi um desafio ganho na última década.

$\mathrm{Na}$ FAB de fluxo contínuo [39] a fonte do espectrómetro é, evidentemente, uma fonte FAB. A injecção da amostra pode ser feita em fluxo controlado do solvente, sendo a matriz adicionada através de um reservatório em que se encontra numa solução com o solvente ou a amostra pode ser adicionada directamente a partir do reservatório em que se encontra juntamente com a matriz e o solvente. Em qualquer dos casos a matriz é adicionada em pequena quantidade $(\approx 5 \%)$. A detecção antes da amos- tra entrar na fonte do espectrómetro fazse normalmente por meio de um detector ultravioleta incorporado num Cromatógrafo Líquido de Alta Pressão, HPLC. A FAB de fluxo contínuo constitui um sistema que permite a identificação em misturas complexas de quantidades vestigiais de compostos polares, pouco voláteis e ou de massa molecular elevada. permitindo ainda seguir a variação da concentração de dada espécie durante processos químicos ou bioquímicos.

Recentemente têm vindo a realizarse estudos para optimização das condiçōes experimentais, incluindo 0 aquecimento da sonda.

\subsection{Situação actual e Perspectivas futuras}

Em virtude das suas potencialidades e grande simplicidade a FAB tem sido e continua a ser uma das técnicas de maior popularidade no domínio da Espectrometria de Massa.

Como conclusão pode dizer-se que esta técnica é usada essencialmente para obter informação de dois tipos:

-0 primeiro, o mais usual e também o mais comum aos outros métodos de ionização, diz respeito à determinação de fórmulas estruturais e quantificação das amostras. A sua aplicação neste campo tem sido vasta com já foi referido. São ainda de prever futuros desenvolvimentos na aplicação desta técnica a outros métodos analíticos.

-0 segundo diz respeito ao estudo de química das soluções e superfícies liquidas. São já vários os estudos que se podem encontrar na literatura, como por exemplo o seguimento da cinética de reacçōes enzimáticas [40] e de substituição isotópica [41] in situ, durante o bombardeamento. Trata-se de um campo que se encontra ainda em desenvolvimento.

Sendo previsível que os mecanismos de produção de iões na fase condensada venham a ser melhor entendidos, é de esperar que no futuro a selecção da matriz se possa fazer de um modo mais racional e que seja possivel um melhor e mais efectivo controlo dos parâmetros que influenciam a obtenção dos espectros FAB.

* Departamento de Química e Bioquímica Faculdade de Ciências da Universidade de Lisboa Campo Grande, 1700 Lisboa

(Texto baseado na Aula de Agregação da Autora) 


\section{REFERÊNCIAS}

1. M. Barber, R.S. Bordoli, R.D. Sedgwick e A.N Tyler. J. Chem. Soc. Chem. Commun. (1981) 325

2. A. G. Harrison e R. J. Cotter em Methods in Enzymology, vol. 193: Mass Spectrometry. Ed. J.A. McCloskey, Academic Press, São Diego. 1990, p.3.

3. R. D. MacFarlane, Acc. Chem. Res., 15 (1982) 286 4. M. W. Thompson, Philos. Mag. 18 (1968) 377 5. P. Sigmund, Phys. Rev., 184 (1969) 383.

6. A. Benninghoven, D. Jaspers e W. Sichtermann, Appl. Phys., 11 (1976) 35

7. W. Aberth e A. L. Burlingame, Anal. Chem., 56 (1984) 2915.

8. J. Franks e A. M. Ghander, Vacuum, 24 (1974) 489

9. A.M. Hogg, Int. J. Mass Spectrom. Ion Phys. 49 (1983) 25

10. M. Barber, R.S. Bordoli, G.J. Elliot, R.D. Sedgwick e A.N. Tyler, Anal. Chem. 54 (1982) 645A

11. M.I. Bruce e M.J. Liddell, Appl. Organomet. Chem., 1 (1987) 191

12. A. Benninghoven, Int. J. Mass Spectrom. Ion Phys., 46 (1983) 459.

13. Q.-W. Huang e G.-L. Wu, Int. J. Mass Spectrom. Ion Phys., 70 (1986) 145

14. L.R. Schronk e R.J. Cotter, Biom. Environ. Mass Spectrom., 13 (1986) 395.
15. J. Inchaouh, J. C. Blais, G. Bolbach e A. Brunot, Int. J. Mass Spectrom. Ion Proc. 61 (1984) 153

16. B.D. Musselmann. J. Throckwatson e C. K. Chang, Org. Mass Spectrom, 21 (1986) 215

17. J. Shiea e J. Sunner, Org. Mass Spectrom. 26 (1991) 38

18. H. Munster, F. Theobald e H. Budzikiewics. Int. J. Mass Spectrom. Ion Proc. 79 (1987) 73.

19. E. Schröder, H. Münster e H. Budzikiewicz, Org. Mass Spectrom., 21 (1986) 707

20. J. Sunner, A. Morales e P. Kebarle, Int J Mass Spectrom. Ion Phys., 86 (1988) 169.

21. H.R. Morris, M. Panico e N.J. Haskins, Int. J. Mass Spectrom. Ion Phys., 46 (1983) 363.

22. A.J. Alexander e A.M. Hogg. Int. J. Mass Spectrom. Ion Proc. 69 (1986) 311

23. J.D. Reynolds e K.D. Cook, J. Am. Soc. Mass Spectrom., 1 (1990) 149.

24. C. Fenselau e R. J. Cotter, Chem. Rev, 87 (1987) 501.

25. E. De Pauw, A. Agnello e F. Derwa, Mass Spectrometry Reviews, 10 (1991) 283.

26. J.L. Gower, Biomed. Mass Spectrom., 12 (1985) 191

27. K.D. Cook, P.J. Todd e D.H.Friar, Biom. Environ. Mass Spectrom., 18 (1989) 492

28. M.H. Florêncio e W. Heerma, Org. Mass Spectrom.. 28 (1993) 657.
29. A. Malorni, G. Marino e A. Miloni, Biomed. Environ. Mass Spectrom., 13 (1986) 477.

30. W.V. Ligon, Jr. em Biological Mass Spectro metry Ed. A.L. Burlingame e J.A. McCloskey, Elsevier, Amesterdão, 1989, p. 61

31. S. Naylor, A.F. Findeis, B.W. Gibson e D.H Williams. J. Am. Chem. Soc., 108 (1986) 6359.

32. W.V. Ligon, Jr. e S.B. Dorn, Int. J. Mass Spectrom. Ion Proc... 57 (1984) 75

33. M.Barber, R.S. Bordoli, G.J. Elliot, R. D. Sedgwick e A.N. Tyler, J. Chem. Soc., Faraday Trans. 1.79 (1983) 1249

34. W.V. Ligon, Jr. e S.B. Dorn. Int. J. Mass Spectrom. Ion Proc., 61 (1984) 113

35. C.W. Kazakoff, R.T.B. Rye e 0.S. Tee, Can J. Chem., 67 (1989) 183

36. R.L. Cerny e M.L. Gross, Anal. Chem. $\mathbf{5 7}$ (1985) 1160 (1985)

37. J.L. Aubagnac, R.M. Claramunt e D. Sanz. Org. Mass Spectrom., 25 (1990) 293.

38. J.N. Kyranos e P. Vorous, Biom. Environ. Mass Spectrom., 19 (1990) 628.

39. R.M. Caprioli (Editor)Continuous-Flow Fast Atom Bombardment Mass Spectrometry, John Wiley, 1990.

40. M. E. Harrison e M. A. Baldwin, Org. Mass Spectrom., 24 (1989) 689

41. S. Verma, S. C. Pomerantz, S. K. Sethi e J. A McCloskey, Anal. Chem., 58 (1986) 2898

\section{EII TPECTRO}

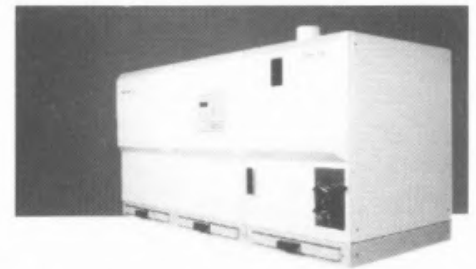

SPECTROFLAME MODULA

ICP para análise simultânea e/ou sequêncial de elementos químicos em soluçāo.

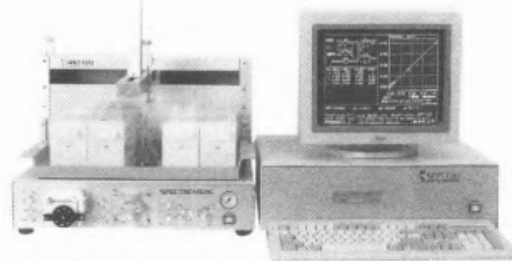

\section{SPECTROMERC}

Analisador de mercúrio para operacão manual, automática ou acoplado ao ICP

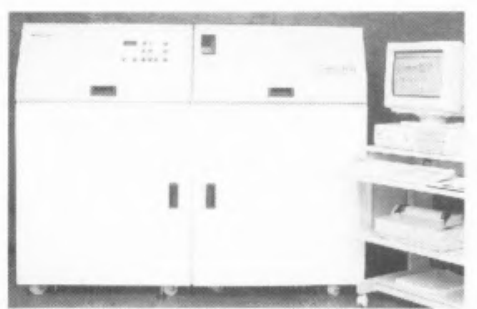

SPECTROMASS - ICP

Espectrómetro de massa - ICP para análise de vestigios de elementos e isótopos.

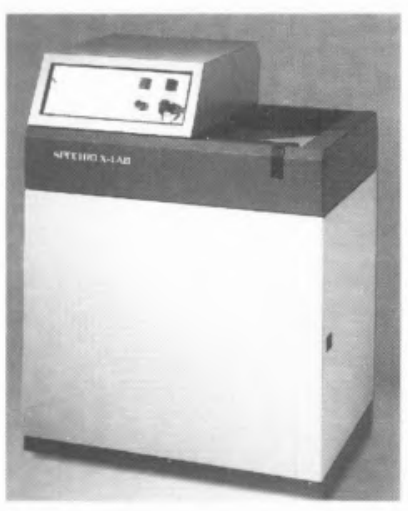

\section{X-RAY}

Espectrómetro de fluorescência de energia dispersiva de Raio-X para determinação de elementos químicos em amostras sólidas e líquidas.

\section{equipamentos de análise e ensalo, LDA.}

Sede: Rua do Real, 1210-A/B - Tels.: (02) 9486905 - 94868689486847 - Fax: (02) 9486132 MOREIRA - GUARDA • 4470 MAIA FILIAL: Campo Mártires da Pátria, 110 - $1^{\circ}$ - Tels.: (01) 3560454 - 3527293 - 3528541 - Fax: (01) 3528752 • 1150 LISBOA 